\title{
ANÁLISE DE UMA CARTILHA INSTITUCIONAL EM UMA ABORDAGEM MODULAR DA COMPLEXIDADE DO DISCURSO
}

\author{
Gustavo Ximenes CUNHA ${ }^{1}$
}

Resumo: Este artigo aproxima a Análise do Discurso e os Estudos Organizacionais, porque considera necessário compreender as organizações (públicas ou privadas) de uma perspectiva do discurso. Para evidenciar a pertinência dessa aproximação, apresentamos uma análise de uma cartilha em que uma agência reguladora do Governo Federal, a ANP, dialoga com agentes do mercado. Desenvolvido à luz do Modelo de Análise Modular do Discurso, o estudo permitiu identificar a imagem que a ANP projeta de si ao interagir, por meio da cartilha, com um setor da sociedade. Com o estudo, obtivemos informações relevantes acerca (i) do contexto de produção e recepção da cartilha, (ii) das imagens recíprocas construídas por meio desse discurso e (iii) de características do processo de negociação entre o Governo (ANP) e a Sociedade (os agentes do mercado).

Palavras-chave: Análise do Discurso. Estudos Organizacionais. Modularidade.

\section{Introdução}

Neste trabalho, parte-se do pressuposto de que a aproximação da Análise do Discurso e dos Estudos Organizacionais é oportuna, tendo em vista a existência de fenômenos do domínio organizacional/institucional que só se deixam apreender mediante a consideração do discurso. Mais especificamente, essa aproximação se justifica pelo fato de que as organizações públicas e/ou privadas são sistemas sociais, cujas relações interpessoais e interinstitucionais são sempre reguladas e constituídas por discursos (CHIAPPINI, 2004; GRANT et al., 2004). Nessa perspectiva, os discursos são um meio privilegiado para se conhecer as relações que se dão entre diferentes agentes, sejam estes profissionais específicos, sejam as próprias organizações.

\footnotetext{
${ }^{1}$ Professor Doutor da Faculdade de Letras da Universidade Federal de Minas Gerais (UFMG), Belo Horizonte, Minas Gerais, Brasil. E-mail: ximenescunha@yahoo.com.br
} 
Nos Estudos Organizacionais, a importância do discurso é reconhecida a ponto de muitos autores defenderem que as organizações não devem ser entendidas como uma entidade concreta (um objeto do mundo), mas sim como um efeito ou uma produção do discurso (um objeto de discurso). Conforme Mumby e Clair (1997, p. 181, grifo do autor), "Quando falamos de discurso organizacional, não simplesmente nos referimos ao discurso que ocorre na organização. Ao contrário, sugerimos que as organizações existem somente como seus membros as criam através do discurso".

Por meio do discurso organizacional, os participantes da interação são sempre levados, consciente ou inconscientemente, a estabelecer entre si diferentes tipos de relações, perpetuando, negociando ou enfrentando, por exemplo, situações de conflito e de dominação, preconceitos, bem como disputas por poder. Essas relações, sempre marcadas do ponto de vista ideológico, dizem respeito basicamente à negociação de imagens (faces e territórios no sentido de Goffman) e de lugares ${ }^{2}$ e têm basicamente como fim levar o outro agente a rever ou manter pontos de vista para realizar determinadas ações, geralmente em benefício do produtor do discurso.

Em todos os discursos organizacionais, essa negociação de imagens e lugares tem impacto sobre os recursos verbais e não verbais escolhidos para sua construção. Nessa perspectiva, esses recursos constituem estratégias discursivas que um agente emprega para se apresentar de determinada forma diante do outro, criando e preservando uma autoimagem (face), para agredir ou preservar a face do outro e para se colocar em determinado lugar (superior ou inferior) em relação ao outro, tendo como objetivo final levá-lo a mudar sua concepção de mundo para agir de determinada maneira.

Como se vê, as propriedades linguísticas, textuais e visuais dos discursos constituem elementos de primeira importância para o conhecimento das organizações ou da maneira como a produção e a circulação dos discursos em dada organização refletem as relações interpessoais e interinstitucionais dessa organização. Em outros termos, as propriedades linguísticas, textuais e visuais permitem conhecer as características situacionais (o contexto) das interações em domínio organizacional.

Nessa perspectiva, este trabalho procura estabelecer aproximações significativas entre a Análise do Discurso e os Estudos Organizacionais. Inicialmente, apresentaremos o modelo teórico e metodológico da Análise do Discurso com o qual procederemos ao estudo, o Modelo de Análise Modular do Discurso. Em seguida, apresentaremos uma proposta de análise de um

\footnotetext{
${ }^{2}$ As noções de face, território e lugares serão definidas mais adiante.
} 
discurso organizacional à luz desse modelo. O discurso analisado será uma cartilha veiculada pela Agência Nacional do Petróleo, Gás Natural e Biocombustíveis (ANP). Por meio dessa análise, ofereceremos um exemplo de como a Análise do Discurso pode contribuir para lançar luz sobre características importantes do discurso organizacional.

\section{O Modelo de Análise Modular do Discurso}

Desenvolvido na Universidade de Genebra por uma equipe de pesquisadores liderada por Eddy Roulet, o Modelo de Análise Modular do Discurso é uma abordagem teórica e metodológica para a descrição e a explicação da organização do discurso. A versão atual do modelo modular é o resultado de mais de vinte anos de pesquisas, ao longo dos quais pesquisadores como Filliettaz, Grobet, Burger, Auchlin, Moeschler e Rossari, além do próprio Roulet, evoluíram de um modelo restrito, focado essencialmente na estruturação e na articulação dos atos de fala em conversações (ROULET et al., 1985), para uma abordagem interacionista que visa dar conta, de maneira bastante precisa, das informações implicadas na produção e na interpretação de toda forma discursiva (oral, escrita, monologal, dialogal ou polilogal), bem como da forma como essas informações se combinam em discursos autênticos e não fabricados pelo próprio analista ${ }^{3}$.

Do ponto de vista teórico, o fato de o modelo modular se inserir na corrente interacionista dos estudos da linguagem dá a ele especificidades que o diferenciam de outras abordagens do campo da Análise do Discurso. Ao se definir como um modelo interacionista, o modelo modular busca contribuições da Análise da Conversação de orientação etnometodológica (SACKS; SCHEGLOFF; JEFFERSON, 2003[1974]), da Pragmática (GRICE, 1979, AUSTIN, 1962; BROWN; LEVINSON, 1983), da Sociolinguística (LABOV; FANSHEL, 1977), da Microssociologia (GOFFMAN, 2011), abordagens para as quais o objeto de estudos privilegiado e cientificamente pertinente é a interação face a face e o fenômeno central de investigação são os atos de fala, bem como os processos emergentes de negociação identitária e de estruturação da conversa.

Entretanto, a filiação do modelo a essa mesma corrente de estudos não impede que seus pesquisadores considerem que as práticas discursivas são reguladas por expectativas sociais e históricas, as quais fazem com que os estudos focados apenas ou principalmente nos processos emergentes de estruturação da conversação precisem ser reconsiderados num

\footnotetext{
${ }^{3}$ Esclarecimentos mais aprofundados sobre as diferentes etapas de formulação do Modelo de Análise Modular do Discurso podem ser obtidos em Roulet (1999) e Roulet, Filliettaz e Grobet (2001).
} 
quadro teórico mais amplo (BURGER, 1997). Baseando-se especialmente em Bakhtin/Volochinov (1986[1929]), o modelo considera que a construção do discurso é condicionada por normas sociais, tais como os gêneros do discurso, e pelos papéis sociais definidos institucionalmente na sociedade. É também sob o impacto das reflexões de Bakhtin/Volochinov, mas também de Benveniste (1976) e de Ducrot (1987) que, para o modelo modular, todo discurso é dialógico em sua essência, ainda que produzido por um único locutor. Assim, todo discurso é sempre uma resposta a discursos previamente produzidos e é elaborado em vista de um interlocutor efetivo ou potencial ${ }^{4}$. Essa perspectiva social e histórica permite ao modelo expandir seu campo de estudos, buscando desenvolver conceitos teóricos e instrumentos de análise para estudar não só interações face a face, mas também interações entre interlocutores em que se verifica uma defasagem espacial e temporal.

As contribuições dos autores mencionados (Bakhtin/Volochinov, Benveniste e Ducrot) são decisivas para fazer com que o modelo ultrapasse uma perspectiva excessivamente restrita da interação e adote uma concepção mais complexa do discurso, o qual passa a ser definido como "interação verbal situada" (ROULET; FILLIETTAZ; GROBET, 2001, p. 34). São essas contribuições que permitem entender o modelo modular como uma abordagem interacionista que amplia a perspectiva mais restrita da Análise da Conversação e de teorias da Pragmática e que, por isso mesmo, encontra afinidades com abordagens como o Interacionismo Sóciodiscursivo (BRONCKART, 2007) e a Teoria Semiolinguística (CHARAUDEAU, 2009) e com autores como Kerbrat-Orecchioni (2008), Vion (1992) e Adam (1997).

Porque o modelo se insere nessa vertente ampliada do interacionismo, algumas orientações teóricas importantes lhe servem de fundamento. Com base em Roulet (ROULET; FILLIETTAZ; GROBET, 2001), adotar um quadro interacionista implica:

- recusar que a comunicação se reduza a uma simples transmissão de informações entre sujeitos desvinculados do contexto histórico e social;

- $\quad$ reconhecer que a função primeira da linguagem é a comunicação, sendo secundária a função de representação;

- $\quad$ adotar a hipótese de que toda comunicação é uma interação, em que ocorre uma negociação permanente entre os interactantes;

\footnotetext{
${ }^{4}$ Para o modelo, o discurso é sempre dialógico e nunca monológico, pelas razões apontadas, mas, no que se refere à sua realização material, ele pode ser dialogal, se produzido por dois locutores, ou monologal, se produzido por um só.
} 
- $\quad$ considerar que a ação linguageira é primeira em relação à língua, "que se desenvolveu progressivamente ao fio das negociações entre os interactantes de uma comunidade" (ROULET; FILLIETTAZ; GROBET, 2001, p. 28);

- adotar, com Bakhtin/Volochinov, uma perspectiva metodológica de análise descendente;

- $\quad$ estudar discursos autênticos e não exemplos criados pelo analista a partir das necessidades de seu modelo teórico e de suas hipóteses;

- $\quad$ reconhecer que toda língua constitui um sistema formado por subsistemas embotados uns nos outros e permeáveis entre si, os quais dizem respeito a estruturações abstratas de modalidades do funcionamento da língua;

- distinguir os aspectos esquemáticos e os aspectos emergentes da interação, mostrando que se, por um lado, o discurso é condicionado por expectativas e representações sócio-históricas, por outro, essas mesmas expectativas e representações são negociadas e avaliadas pelos interactantes.

Como se pode observar por essas balizas ou princípios teóricos, a complexidade do modelo vem da sua proposta de estudar o discurso como um fenômeno dinâmico, histórico e social e, ao mesmo tempo, estruturado e estruturante. Para o modelo modular, o discurso é estruturado, já que todos os níveis de sua organização (situacional, textual e linguístico) se caracterizam por unidades que estabelecem relações hierárquicas entre si. É por isso que as estruturas sintática (nível linguístico), hierárquica (nível textual) e referencial (nível situacional) são, segundo Roulet (1995), as estruturas que sustentam o discurso e ocupam um lugar central nos estudos do modelo modular, sendo um dos objetivos dessa abordagem propor instrumentos de análise para estudá-las.

Do ponto de vista metodológico, a busca do modelo modular por integrar de forma rigorosa as dimensões linguística, textual e situacional do discurso, evitando uma concepção restrita da interação, é a responsável pela adoção de uma metodologia modular. Nesse sentido, vale ressaltar que a vocação metodológica do modelo é uma decorrência de suas concepções e filiações teóricas, não devendo ser entendida a modularidade como uma metodologia ad hoc, cujo interesse seria somente o de reunir, numa mesma abordagem, teorias vindas de horizontes diversos e, por isso, de conciliação difícil (ou impossível).

Conforme Roulet (1995), as hipóteses ditas externas (concepções oriundas de outras propostas teóricas), ao serem assimiladas pelo modelo, são reinterpretadas à luz dos princípios interacionistas mencionados, visando dar conta da organização do discurso. Esse movimento 
de assimilação e de reinterpretação de outras abordagens ocorreu em todas as etapas de formulação do modelo e permitiu considerar e avaliar, sob uma nova perspectiva, noções como as de ato de fala (Austin, Searle), tópico (Danes), sequência discursiva (Adam), tipo de discurso (Bronckart), face e território (Goffman), dialogismo e polifonia (Bakhtin/Volochinov, Ducrot), estrutura hierárquica (Pike, Sinclair, Coulthard), contrato de comunicação (Charaudeau), conector e relações de discurso (Ducrot, Anscombre) etc.

Enquanto hipótese metodológica e não enquanto hipótese cognitiva sobre o funcionamento da mente, a modularidade aplicada aos estudos do discurso implica uma dupla exigência:

a) decompor a organização complexa do discurso em um número limitado de sistemas (ou módulos) reduzidos a informações simples e b) descrever de maneira tão precisa quanto possível a forma como essas informações simples podem ser combinadas para dar conta das diferentes formas de organização dos discursos analisados. (ROULET; FILLIETTAZ; GROBET, 2001, p. 42).

Na versão atual do modelo modular, são considerados cinco módulos de base (lexical, sintático, hierárquico, interacional, referencial), cada um se ocupando de um domínio específico de informações. Esses módulos tratam de informações relativas a cada dimensão do discurso. A dimensão situacional é estudada pelos módulos interacional e referencial; a dimensão textual é estudada pelo módulo hierárquico; e a dimensão linguística é estudada pelos módulos lexical e sintático.

Na produção e na interpretação dos discursos, as informações modulares se combinam em diferentes formas de organização, cujo papel é o de descrever e explicar os diferentes planos de que o discurso se compõe. Como exemplo, podemos pensar nas relações de discurso (argumento, contra-argumento, reformulação, tempo etc.) e em sua marcação por conectores e estruturas sintáticas. Não é possível compreender esse plano do discurso estudando apenas os conectores ou as estruturas sintáticas. Também não permite compreendêlo o estudo exclusivo da estrutura do texto ou das informações nele ativadas. $\mathrm{O}$ estudo dessas relações de discurso necessita integrar, numa mesma abordagem, informações lexicais, sintáticas, textuais (hierárquicas) e referenciais no interior da forma de organização relacional. O esquema abaixo representa a arquitetura global do modelo. Na coluna à esquerda, estão os módulos. Nas outras duas, encontram-se as formas de organização. 
Figura 1 - Arquitetura do Modelo de Análise Modular do Discurso

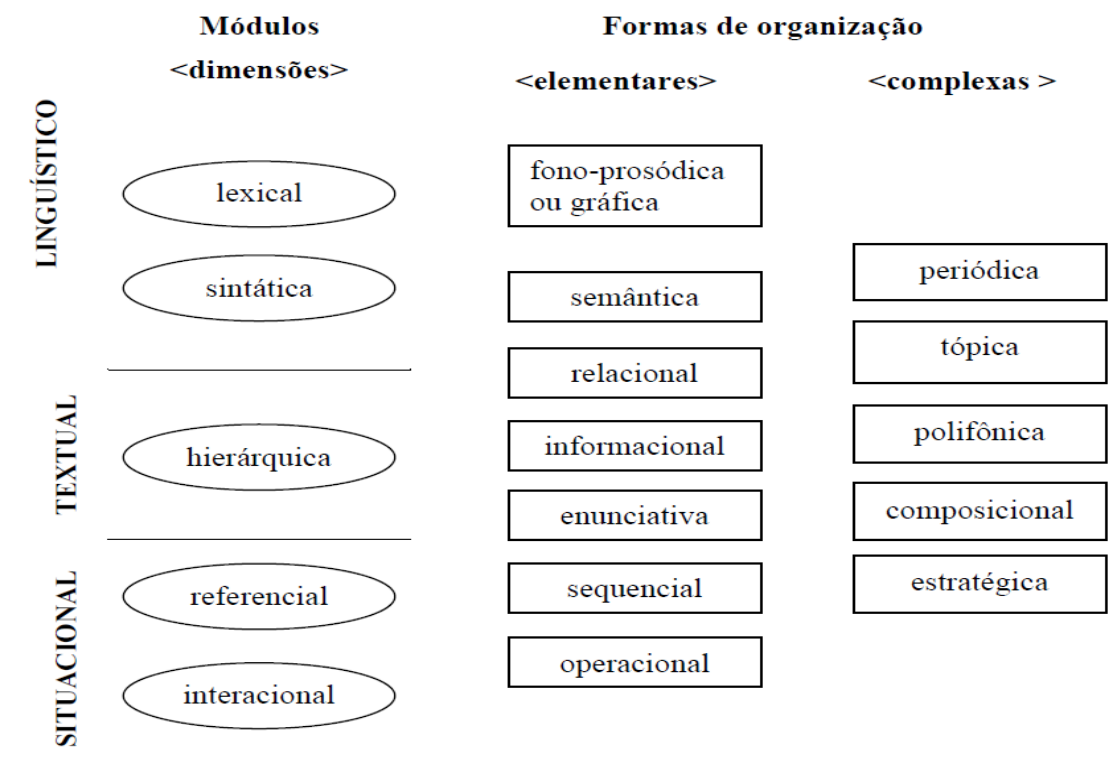

Fonte: Cunha (2013, p. 62)

\section{Análise de uma cartilha institucional}

Com base no Modelo de Análise Modular do Discurso, apresentamos neste item um estudo que busca investigar qual é a imagem que uma agência reguladora do Governo Federal (ANP) constrói para si ao dialogar com empresas privadas por meio de uma cartilha institucional. Com isso, será possível evidenciar como essa cartilha materializa um aspecto particular da complexa e multifacetada relação entre o Governo, representado por uma organização (a ANP), e a sociedade, representada por um setor específico (os agentes do mercado).

A hipótese que nos guia é a de que o Governo, na construção da cartilha, se vale de recursos linguísticos e textuais para construir para si a imagem (face) de um Estado regulamentador, interessado apenas na execução eficiente de determinadas operações, e para colocar-se numa posição superior em relação às empresas com que dialoga. Nesse sentido, esses recursos linguísticos e textuais funcionam como estratégias discursivas para a gestão de faces, territórios e lugares e revelam o papel que a ANP, enquanto instância governamental, reivindica para si no diálogo com a sociedade ou com um setor específico da sociedade. 
Na cartilha selecionada ${ }^{5}$, a ANP orienta os agentes do mercado a realizar um conjunto de ações consideradas adequadas para armazenamento e transporte de óleo diesel B, que é o óleo diesel em cuja composição há $5 \%$ de biodiesel. Na Figura 2, apresentamos a capa da cartilha.

Figura 2 - Capa da cartilha da ANP

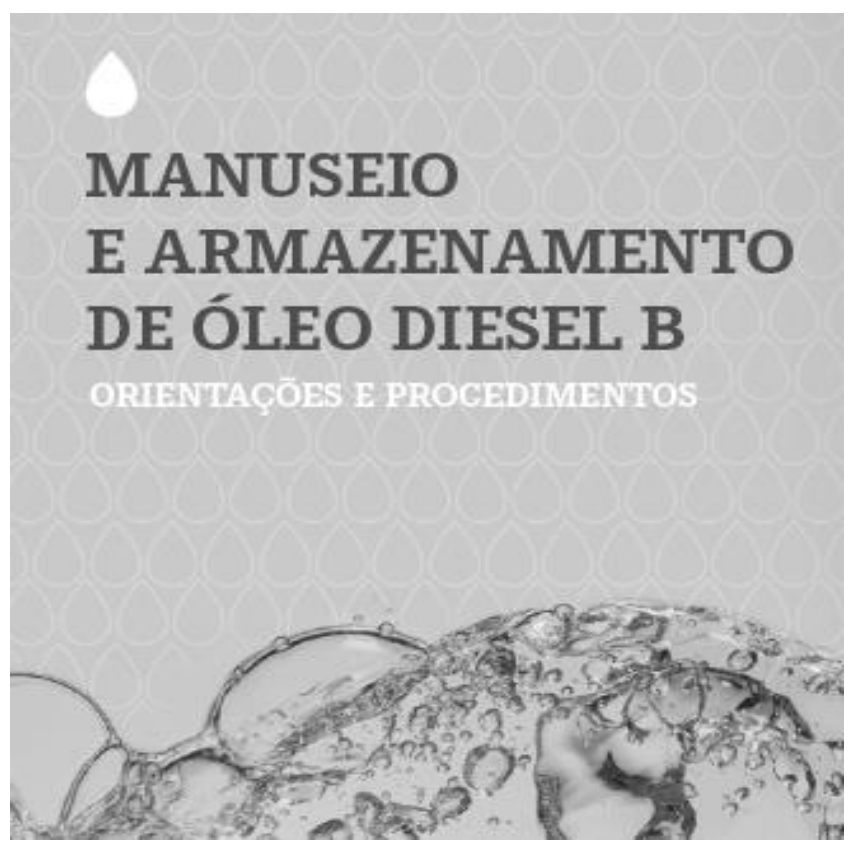

Fonte: ANP <http://www.anp.gov.br >

Em algumas seções da cartilha, a ANP orienta como manusear e armazenar o óleo diesel B, como ocorre na seção "Orientações e procedimentos" (Figura 3). 
Figura 3 - Seção "Orientações e procedimentos"

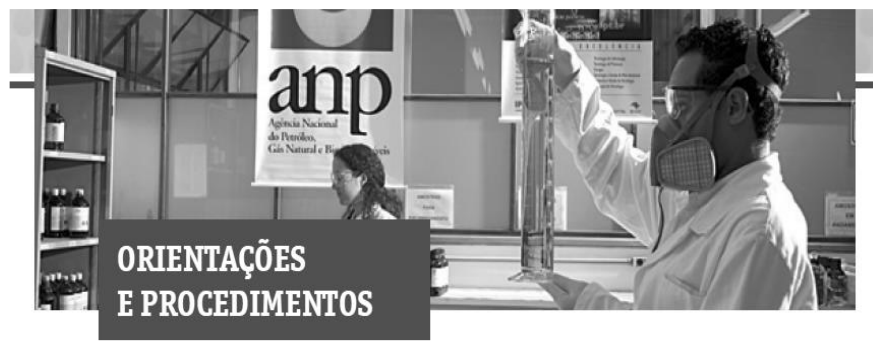

\begin{abstract}
- É necessário que toda a cadeia de abastecimento incorpore às rotinas do óleo diesel B os mesmos cuidados inerentes ao manuseio e ao armazenamento do óleo diesel A ( $100 \%$ de óleo diesel de petróleo).
\end{abstract}

- É imprescindível a aquisição e uso da norma ABNT NBR $15.512^{*}$, que estabelece os
requisitos e procedimentos para o armazenamento, transporte, abastecimento e controle
de qualidade de biodiesel e/ ou mistura óleo diesel/biodiesel.

Fonte: ANP <http://www.anp.gov.br>

Já em outras seções, a ANP orienta como estocar e transportar o óleo diesel B, como na seção "Estocagem e transporte" (Figura 4).

Figura 4 - Seção "Estocagem e transporte"

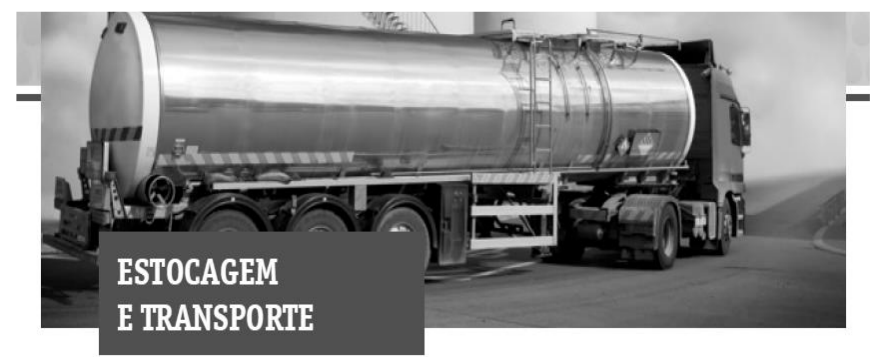

- 0 óleo diesel B pode ser estocado por longo período visto que 0 atendimento às boas práticas de manuseio e armazenamento possibilita a manutenção da sua qualidade. 0 combustível estocado, desconsiderando-se tais práticas, pode se deteriorar e apresentar formação de material insolúvel.

- A presença de material insolúvel no combustível pode levar à obstrução de filtros e injetores, além de favorecer a formação de depósitos no sistema de combustão e a ocorrência de corrosão.

Fonte: ANP <http://www.anp.gov.br>

Para investigar a imagem que a ANP constrói para si por meio dessa cartilha institucional ao dialogar com um setor da sociedade, será preciso seguir um percurso de 
análise específico. No modelo modular, o estudo da negociação de imagens identitárias se faz em termos de relações de faces, territórios e lugares, no interior da forma de organização estratégica. Essa forma de organização, que será explicada adiante, resulta da combinação de informações do módulo referencial, sobre o enquadre acional, com informações de outros módulos e de formas de organização.

Dessa forma, o percurso de análise escolhido para estudar a cartilha se inicia com o estudo do enquadre acional, que define o contexto. Em seguida, já no interior da forma de organização estratégica, as informações resultantes do estudo do enquadre acional serão combinadas de maneira progressiva e não simultânea com as informações dos módulos sintático e hierárquico e das formas de organização sequencial, informacional e composicional. Essas diferentes etapas da análise serão apresentadas na sequência deste trabalho.

\section{Módulo referencial: o estudo do enquadre acional}

Esse módulo, como mencionado na apresentação do modelo modular, estuda as relações que o discurso mantém com o mundo em que se insere, bem como as relações que mantém com os mundos que representa. Um dos instrumentos desse módulo para estudar o mundo em que o discurso se insere ou o contexto é o enquadre acional. $\mathrm{O}$ engajamento dos agentes numa dada interação não acontece de forma desorganizada. Por isso, esse enquadre busca reconstruir as propriedades ligadas aos agentes, as quais são responsáveis, em grande medida, pela regulação das produções verbais (FILLIETTAZ, 2000). No enquadre acional, a descrição das propriedades de uma situação se faz com a articulação de quatro parâmetros, que são os enjeux comuns, as ações participativas, as posições acionais e os complexos motivacionais.

- $\quad$ Os enjeux comuns se referem à finalidade da interação, em torno da qual os agentes estruturam seu engajamento ou associação momentânea.

- $\quad$ As ações participativas dizem respeito aos objetivos individuais de cada um dos agentes ou às "parcelas interdependentes de responsabilidade que cabem a cada um dos interactantes na emergência de um enjeu comum" (ROULET; FILLIETTAZ; GROBET, 2001, p. 114).

- Já as posições acionais se referem à representação das identidades que são efetivamente assumidas pelos agentes e que legitimam suas ações. Para descrever as posições 
acionais dos agentes, é preciso levar em conta o status social de cada um deles, os papéis praxiológicos ligados às ações participativas, bem como as faces e os territórios em jogo.

- $\quad$ Os complexos motivacionais, por fim, remetem às razões exteriores à situação que levam cada um dos agentes a participar da interação.

As noções de face e de território são especialmente relevantes para o estudo da forma de organização estratégica. Por isso, serão explicadas mais detidamente.

Goffman (2011, p. 13-14) define a noção de face como "o valor social positivo que uma pessoa efetivamente reivindica para si mesma através da linha que os outros pressupõem que ela assumiu durante um contato particular". Ainda, a face "é a imagem do eu delineada em termos de atributos sociais aprovados" (2011, p. 14). Ressaltando o aspecto social da noção de face, Valério (2003, p. 33) nota que a face de um agente "não é característica sua, mas sim um construto socialmente estabelecido, a expressão social de seu 'eu' individual". Por se referir ao jogo de construção de imagens recíprocas desenvolvido na interação, essa noção se refere a um processo de natureza dramatúrgica.

Já a noção de território diz respeito aos direitos que cada pessoa reivindica para si e à defesa desses mesmos direitos. Os direitos que formam o território de cada um constituem um campo de objetos ou uma reserva, cujos limites são habitualmente preservados e defendidos. O território se refere não só ao território físico, à "porção de espaço que cerca um indivíduo" (GOFFMAN, 1973, p. 44), mas também abrange partes do corpo e objetos de uso pessoal. Além disso, o território engloba reservas de informações, ou seja, informações às quais o indivíduo tenta controlar o acesso. Engloba ainda o direito que tem o indivíduo de controlar quem pode lhe endereçar a fala ou o direito que tem um grupo de pessoas de proteger-se da indiscrição alheia.

No modelo modular, face e território são noções utilizadas para a compreensão da construção de imagens que ocorre em todo processo interacional, seja este materializado pelo diálogo face a face, seja pela escrita institucional.

Como resultado da combinação dos parâmetros apresentados, o enquadre acional da interação materializada na cartilha da ANP pode ser representado por meio da Figura 5. 
Figura 5 - Enquadre acional

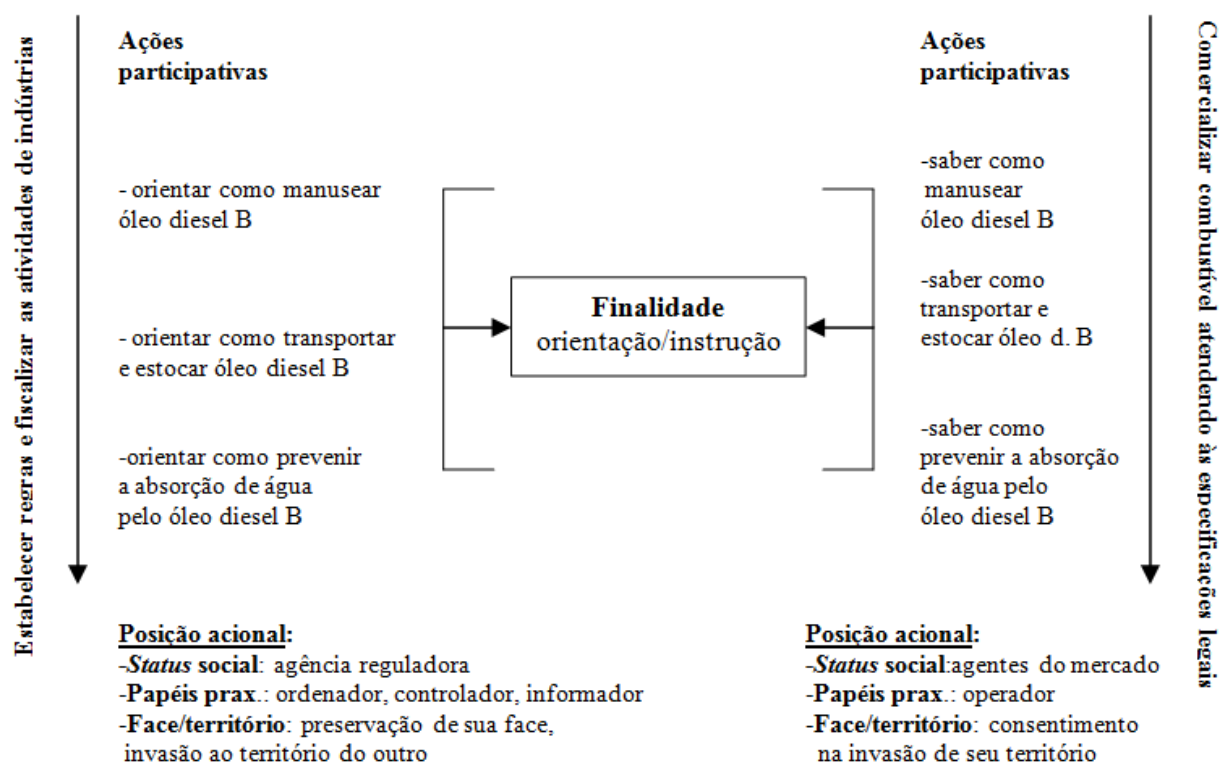

Fonte: Elaboração própria

O complexo motivacional especifica as razões de agir das instâncias envolvidas na interação. Assim, a agência reguladora deve estabelecer regras e fiscalizar as atividades das empresas reguladas ${ }^{6}$. Já os agentes do mercado devem comercializar combustível, atendendo às especificações legais, sob pena de punições, suspensões de contratos etc. São esses os motivos que levam as instâncias a participar da interação materializada na cartilha. Ou seja, são essas as razões que levam à elaboração e à leitura da cartilha.

Nessa interação, a finalidade comum, aquela que responde à questão estamos aqui para fazer o quê?, é a de orientação/instrução. As instâncias se unem momentaneamente guiadas por essa finalidade, que tem ligação direta com os complexos motivacionais. Porque a agência deve estabelecer regras e fiscalizar atividades de organizações reguladas e porque os agentes do mercado devem comercializar combustível atendendo às especificações legais, compreende-se que a finalidade da interação que une essas instâncias seja a de orientação/instrução e não, por exemplo, a de informação, característica das reportagens.

Essa finalidade possui uma dimensão mais sócio-objetiva do que sócio-subjetiva. Afinal, a interação é orientada mais para "a modificação socialmente regulada de estados de coisas existentes no ambiente físico" (FILLIETTAZ, 2000, p. 76) - o manuseio e o transporte corretos de óleo diesel B - do que para "a busca de um reconhecimento público de experiências passadas subjetivas dos agentes" (idem) e/ou para a apresentação de si.

6 Trata-se de informação colhida no Portal Brasil: <http://www.brasil.gov.br/governo/2009/11/agenciasreguladoras>. Acesso em: 29 out. 2014. 
Entretanto, a dimensão sócio-subjetiva não está excluída da interação entre a ANP e os agentes do mercado, na medida em que é possível reconhecer o emprego por parte da agência reguladora de estratégias de criação, proteção e agressão das faces envolvidas. Entretanto, como mostraremos adiante, essas estratégias estão a serviço da dimensão sócio-objetiva ou são empregadas para convencer o outro da importância ou da obrigatoriedade de realizar ações no mundo.

Para o alcance da finalidade de orientação/instrução, cada uma das instâncias participantes da interação realiza ações particulares, que devem ser entendidas como contribuições individuais à ação conjunta. Dessa forma, ao longo da interação viabilizada pela cartilha, cada instância realiza ações com o fim de alcançar objetivos individuais, os quais, no entanto, são interdependentes. Assim, os agentes do mercado só podem saber como manusear o óleo diesel $\mathrm{B}$ se a agência reguladora informar como realizar o manuseio. A complementaridade dessas ações garante o alcance da finalidade comum da interação.

Quanto às posições acionais, que, como exposto, se referem às identidades assumidas pelas instâncias durante a interação, a instância de produção do discurso assume o status social de agência reguladora. Esse status se mantém ao longo de toda a interação e atribui à instância que o assume a legitimidade para dar ordens, bem como a competência para orientar o leitor na tarefa de manusear combustíveis e dar informações sobre substâncias e procedimentos. Esse status de órgão normatizador constitui, assim, um papel pré-formatado que autoriza aquele que o assume a dar ordens ao outro e que explica a própria seleção do gênero do discurso considerado o mais adequado para o desenvolvimento da interação, a cartilha.

Durante a realização das ações participativas, a agência assume identidades locais que se referem aos papéis praxiológicos e que se ligam a cada uma das ações. Na cartilha, a agência assume principalmente o papel de ordenador ou de uma instância que dá ordens. Mais pontualmente e a serviço desse papel de ordenador, a agência assume ainda o papel de informador, quando realiza as ações de dar informações necessárias à realização dos procedimentos.

Por fim, a agência constrói para si a imagem (face) de instituição autoritária que tem o direito e o dever de dar ordens às organizações reguladas. Essa é a face que a ANP escolhe para interagir com os agentes do mercado. Ao mesmo tempo, tendo em vista o status de agência reguladora, essa instância tem legitimidade para invadir o território do outro, dando ordens a ele ou o obrigando a se comprometer com a realização de ações futuras, sem 
negociações relativas a essa invasão (o que poderia ferir sua face) e sem explicações sobre suas razões para proceder dessa forma (o que poderia revelar seu território).

Por sua vez, a instância de recepção do discurso assume o status social de agentes do mercado, já que é esse o termo que a instância de produção emprega, na cartilha, para se referir ao interlocutor. Como o motivo que leva a agência reguladora a participar da interação é o de fiscalizar as atividades das empresas reguladas, a assunção do status de agentes do mercado por essas organizações implica sua capacidade de compreender as ordens impostas e o dever de obedecer à agência, assumindo implicitamente o compromisso de realizar essas ordens. Em outros termos, a instância de produção, ao assumir o papel de agência reguladora na produção da cartilha, reserva ao outro o papel de agentes do mercado, o que implica, por parte dessa instância, a concordância tácita de uma série de deveres e obrigações.

Na cartilha, a ANP impõe uma série de ordens. Por isso, ao longo da interação, os agentes assumem apenas um papel praxiológico, o de operador. Como as agências reguladoras, surgidas no contexto da privatização, transferem para outras organizações responsabilidades que, antes, eram do Estado (PACHECO, 2006), a instância de recepção é convocada, no discurso da ANP, enquanto agente capaz de realizar operações no mundo e não, por exemplo, enquanto agente capaz de questionar ou negociar as ordens impostas ou de substituir essas ordens por outras.

Tendo em vista esse papel de operador, o agente do mercado entra na interação sabendo que sua face sofrerá ataque (receber ordens é sempre agressivo para a face de quem as recebe) e que seu território será invadido (aceitar ordens é permitir que o outro decida quais ações futuras serão realizadas por quem as aceita).

Feita a análise do enquadre acional (ou do contexto), as informações aqui obtidas serão combinadas, no próximo item, com as de outros módulos e formas de organização, no interior da forma de organização estratégica.

\section{Forma de organização estratégica}

A forma de organização estratégica trata da maneira como os agentes coordenam as relações de faces, territórios e lugares no discurso, passando da descrição à explicação dos comportamentos dos agentes em termos de estratégias (BURGER, 1995). Ou seja, essa forma de organização analisa as estratégias discursivas empregadas pelo produtor do discurso para construir e preservar sua face (autoimagem), defender seu território (domínio privado), preservar ou agredir a face do outro, invadir o território do outro, dominá-lo, colocando-se 
num lugar elevado, ou se deixar dominar, permitindo ao outro que se sobreponha na interação (CUNHA, 2013, 2014).

No estudo das relações de faces e territórios, combinam-se informações acerca dessas noções de face e território, oriundas do enquadre acional, com informações de outros módulos e formas de organização, para verificar, em especial, como os agentes realizam os processos de figuração, isto é, as estratégias para construir uma imagem para si, bem como para reduzir ou intensificar as ameaças às faces e aos territórios.

Já no estudo das relações de lugares, analisa-se a relação vertical ou de dominância entre os agentes, durante o desenvolvimento da interação. Na definição de Kerbrat-Orecchioni (2006, p. 69), “quer a chamemos de 'poder', 'hierarquia', 'dominação' ou 'relação de lugares', essa dimensão remete ao fato de que os parceiros em presença não são sempre iguais na interação". De maneira semelhante, para Lanna (2005, p. 185),

A relação de lugar remete à ocupação mesma do lugar de poder ao longo da interação, caracterizando-se por uma relação dinâmica de dominação relativa entre os interactantes, que podem estar ora na posição dominante, alta ou superior, ora na posição dominada, baixa ou inferior.

Como antecipado na definição do percurso de análise, o estudo da forma de organização estratégica da cartilha da ANP resultará da combinação progressiva da análise do enquadre acional com as análises dos módulos sintático e hierárquico e das formas de organização sequencial, informacional e composicional ${ }^{7}$.

\section{Módulo sintático}

$\mathrm{Na}$ cartilha, é recorrente o emprego de orações modalizadoras, como ocorre neste trecho:

(1) É necessário que toda a cadeia de abastecimento incorpore às rotinas do óleo diesel B...

O segmento destacado constitui uma expressão modalizadora que apresenta estrutura oracional (KOCH, 2008). Isso porque orações como essa indicam as intenções e as atitudes do locutor em relação ao conteúdo proposicional da outra oração, tradicionalmente classificada como subordinada. Conforme Koch (2008, p. 138, grifo nosso), ao utilizar orações

\footnotetext{
${ }^{7}$ Para uma definição geral desses módulos e formas de organização, remetemos o leitor ao item de apresentação do modelo modular. Na sequência deste trabalho, detemo-nos na exposição e discussão das análises.
} 
modalizadoras do tipo das encontradas na cartilha, "o locutor assume total responsabilidade relativamente ao conteúdo asseverado, criando, também, para o interlocutor, o dever de crer; em decorrência, apresenta seu discurso como autoritário, não admitindo contestação.”.

Do ponto de vista estratégico, essas orações, ressaltando o papel de operador a ser assumido pelos agentes do mercado, são bastante agressivas para sua face, porque os colocam na posição de instância à qual é permitido dar ordens e que não tem o direito de contestá-las. Por isso mesmo, por meio dessas orações, reforça-se uma relação vertical de lugares entre alguém que manda (a ANP) e alguém que obedece (os agentes do mercado).

\section{Módulo hierárquico}

O texto da cartilha não simula nenhum diálogo com o interlocutor. Ou seja, a ANP não se preocupa em criar, no discurso, uma situação em que ela e os agentes dialogariam sobre o que fazer e como fazer ou em que a ANP tiraria possíveis dúvidas dos agentes do mercado sobre como agir, como ocorre em cartilhas institucionais voltadas para o cidadão (MOZDZENSKI, 2006). Por isso, todo o texto apresenta uma estrutura de intervenção, que é a unidade monologal máxima, e não apresenta nenhuma troca, que é a unidade dialogal máxima. No processo de negociação que a ANP instaura com seu público-alvo, essa intervenção constitui uma proposição, à qual o outro deve reagir realizando as ações expressas.

A Figura 6 apresenta a macroestrutura hierárquica da cartilha. Verifica-se que toda a cartilha constitui uma grande intervenção (I), que, por sua complexidade estrutural, se compõe de outras intervenções. Tendo em vista o grau relativo de importância dessas intervenções para o desenvolvimento da interação, elas são principais (p), subordinadas (s) ou coordenadas umas em relação às outras ${ }^{8}$.

\footnotetext{
${ }^{8} \mathrm{Na}$ estrutura, a numeração indica que o texto da cartilha foi segmentado em atos. No modelo modular, o ato se refere à menor unidade de análise do texto.
} 
Figura 6 - Macroestrutura hierárquica da cartilha

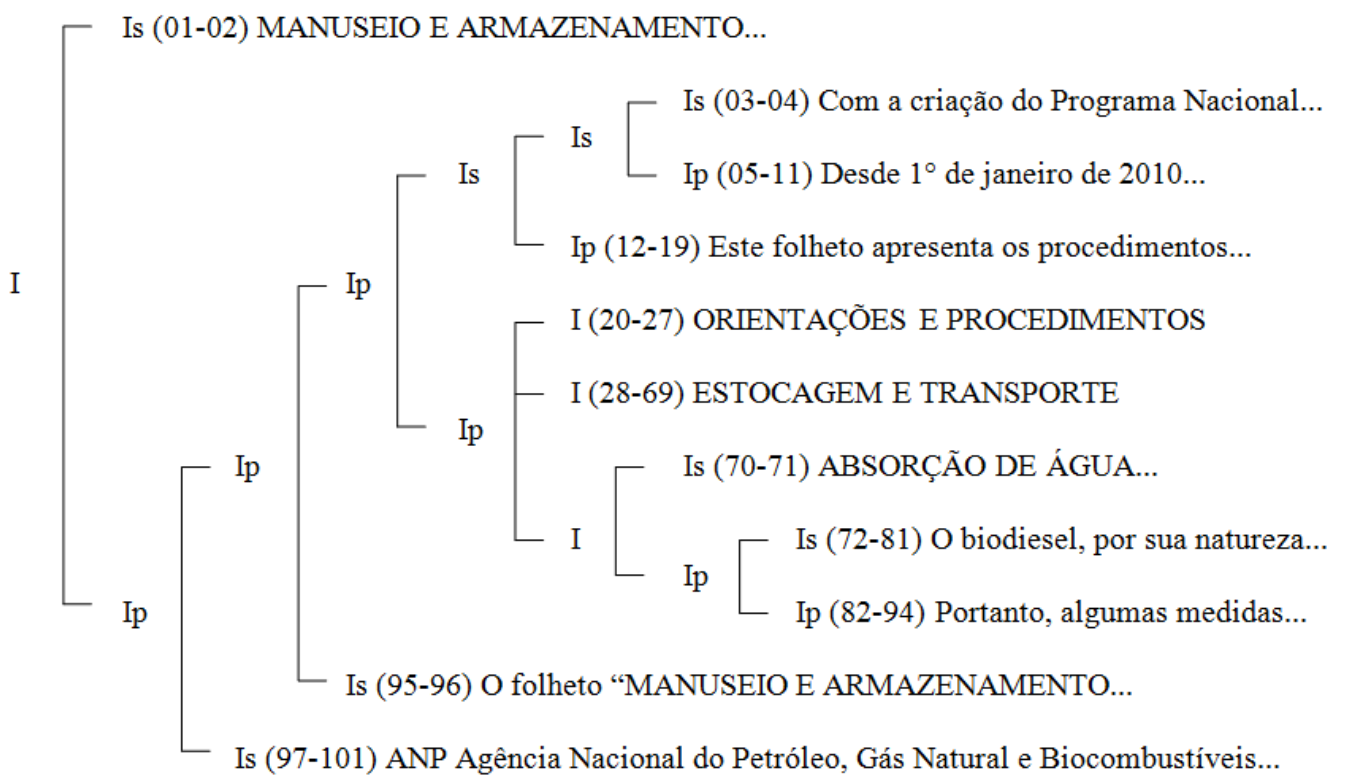

Fonte: Elaboração própria

No plano estratégico, a ausência de trocas, que simulariam a interação com o interlocutor, acentua ainda mais o silêncio deste, o qual em nenhum momento é convocado a trazer suas dúvidas ou opiniões. Por ser todo o texto uma grande intervenção formada por outras intervenções, constata-se que é apenas a ANP quem tem (ou se dá) o direito à fala, em função do status de agência reguladora. Ao interlocutor, reserva-se o direito de ler as ordens, acatá-las e realizá-las no futuro. Com essa ausência de trocas, a ANP consegue, assim, invadir o território do interlocutor, por se dar o direito de ser o único parceiro a tomar a palavra, e agredir sua face, por lhe dar ordens. Consequentemente, ela acentua o desequilíbrio dos lugares ocupados pelos agentes participantes da interação.

\section{Forma de organização sequencial}

$\mathrm{Na}$ cartilha, predominam sequências descritivas. Essas sequências não apresentam as propriedades de seres, lugares ou objetos, mas expõem uma série de ações (ordens) a ser realizadas pelo leitor para o alcance de determinado fim. São, portanto, descrições de ações (ADAM, 1997). 
(2) - Verificar se os tanques e compartimentos de armazenamento e transporte estão isentos de água. - Verificar periodicamente a presença de água. - Manter os tanques de armazenamento preferencialmente na capacidade máxima permitida. - Drenar equipamentos e veículos que não serão usados por longos períodos.

$\mathrm{Na}$ forma de organização estratégica, essas sequências, cujo emprego decorre diretamente da finalidade da interação: orientação/instrução, constituem estratégias discursivas importantes por meio das quais, mais uma vez, a ANP se sobrepõe na interação, mostrando ao interlocutor que o lugar (inferior) que lhe cabe é o de um parceiro mudo, que deve realizar as ordens expressas. Essas sequências funcionam, assim, como recursos adequados para a ANP agredir a face do outro e reforçar seu status de agência reguladora do Estado.

\section{Forma de organização informacional}

$\mathrm{Na}$ cartilha, o tópico dos atos - ou aquilo de que trata cada ato-é predominantemente o óleo diesel B ou são conceitos derivados do óleo diesel B. Em nenhum dos atos, o tópico se constitui de um dos parceiros da interação. Ou seja, em nenhum dos atos da cartilha, a ANP assume a $1^{\mathrm{a}}$ pessoa ou se dirige diretamente ao interlocutor, o que poderia ser feito por meio de itens, como eu, nós, você, seu, como mostra a Figura $7^{9}$ :

Figura 7 - Estrutura informacional de trecho da cartilha

\begin{tabular}{|l|}
\hline $\begin{array}{l}\text { (57) O biodiesel pode dissolver ferrugem e outras impurezas } \\
\text { provenientes de tanques de armazenamento e transporte }\end{array}$ \\
\hline $\begin{array}{l}\text { (58) e, apesar dos efeitos destes contaminantes [ferrugem e } \\
\text { outras impurezas] serem menores no óleo diesel B, }\end{array}$ \\
\hline (59) pelo seu baixo teor de biodiesel [óleo diesel B], \\
\hline $\begin{array}{l}\text { (60) é necessária a verificação dos filtros [dos tanques] } \\
\text { periodicamente, }\end{array}$ \\
\hline (61) de forma a inibir sua obstrução [dos filtros]. \\
\hline
\end{tabular}

Fonte: Elaboração própria

Na única menção ao interlocutor, esse é tratado na terceira pessoa: "A adoção e efetiva aplicação da norma [da ABNT] pelos agentes do mercado é indispensável para garantir a qualidade do combustível”. Além disso, ele não constitui o tópico do ato, mas sim a norma da ABNT.

${ }^{9}$ Os termos em negrito e as informações entre colchetes especificam o tópico de cada ato. 
Essa análise mostra que também o plano informacional do discurso é construído de maneira a acentuar a distância (vertical) de lugares entre os agentes que interagem por meio da cartilha. Afinal, ao abordar preferencialmente a informação óleo diesel $B$ e conceitos dela derivados, a ANP intensifica o silêncio do interlocutor, referido uma única vez e na $3^{\text {a }}$ pessoa. Ao mesmo tempo, não mencionar os parceiros da interação é um recurso que permite à ANP criar um efeito de objetividade e neutralidade, característico dos discursos (como o científico e o jornalístico) em que a instância de produção quer fazer parecer para a instância de recepção que as informações expressas são irrefutáveis ou inquestionáveis (CORACINI, 1991). Assim, a organização informacional da cartilha auxilia a ANP a, no nível estratégico, apresentar-se como uma instituição distante, já que não se implica no discurso, e cujas ordens devem ser obrigatoriamente seguidas.

\section{Forma de organização composicional}

O estudo dessa forma de organização complexa desenvolve a análise da forma de organização sequencial e tem como um de seus objetivos estudar a marcação linguística das sequências discursivas.

A análise da marcação linguística das sequências da cartilha revelou que nelas há a presença abundante de itens lexicais que manifestam efeitos argumentativos, isto é, itens que contribuem para tornar mais argumentativas principalmente as sequências descritivas (sequências de ações). Esses itens são, em especial, conectores argumentativos, verbos na voz passiva e verbos flexionados no presente do indicativo.

- Conectores argumentativos: na cartilha, conectores como também, porque, de forma a, como, desta forma sinalizam que as informações que introduzem são argumentos (justificativas, exemplos, conclusões) para a realização das ações expressas. O emprego frequente desses conectores revela, assim, a busca da ANP por convencer os agentes do mercado a realizar essas ações.

(3) Também deve ser evitado o contato do óleo diesel B com materiais incompatíveis, como certos tipos de elastômeros e metais, de forma a minimizar a incorporação de contaminantes ao combustível.

- Verbos na voz passiva: na cartilha, a voz passiva exerce uma dupla função. Primeiro, ela realça a ação a ser realizada pelo leitor, evidenciando que o foco está na ação e não no agente por ela responsável. Segundo, ela acentua o silêncio dos agentes do mercado e o fato de que o que se espera destes (meros operadores) é a realização irrefletida, automática 
da ação expressa. Isso porque, nessas construções, os agentes responsáveis pelas ações (os agentes do mercado) nunca são mencionados. Essa segunda função se intensifica com a presença, também recorrente na cartilha, do verbo modal deve nas construções passivas.

(4) Deve ser feita semanalmente a drenagem de produto remanescente no fundo do tanque de armazenamento.

- Verbos no presente do indicativo: com esses verbos, o autor evidencia para o leitor que as informações (ordens) expressas são válidas no agora da enunciação, o que dá ao leitor, alvo das ordens, a obrigação de realizá-las, sem tempo para questionamentos ou ponderações.

(5) É imprescindível a aquisição e uso da norma ABNT NBR 15.512.

O uso desses elementos linguísticos (conectores argumentativos, verbos na voz passiva e verbos flexionados no presente do indicativo), tornando as sequências descritivas mais argumentativas, acentua a hierarquia entre os parceiros da interação e evidencia que, para a ANP, o papel praxiológico a ser desempenhado pelos agentes do mercado na interação é mesmo o de operador. Com esses elementos, as ordens expressas nas sequências de ações tornam-se mais agressivas para a face do interlocutor e mais invasivas de seu território.

A seguir, faremos um balanço das análises realizadas até o momento, focalizando suas implicações para a identificação da imagem da ANP que emerge da cartilha.

\section{Forma de organização estratégica: a gestão de faces, territórios e lugares no discurso}

Tendo em vista o contexto de produção e de recepção da cartilha, descrito por meio do enquadre acional, a ANP é levada a utilizar recursos linguísticos e textuais, pertencentes a diferentes planos da organização do discurso, como estratégias discursivas para criar e preservar a imagem de organização regulamentadora e autoritária. Assim, as estratégias escolhidas the permitem invadir o território do interlocutor, organizações privadas, colocando-as em um lugar inferior de parceiro mudo (sem direito à fala) e ignorante dos tópicos abordados e colocando-se numa posição superior em relação a elas. Ao invadir o território do leitor de modo ostensivo, estabelecendo uma relação assimétrica entre um que manda e outro que obedece, a ANP revela não se importar em agredir a face do interlocutor ou dos agentes do mercado.

Assim, na relação interinstitucional materializada na cartilha, a ANP, por meio das estratégias discursivas descritas, constrói para si uma imagem autoritária de instância regulamentadora/ordenadora do Governo, imagem que condiz com seu status de agência 
reguladora criada para controlar e supervisionar a atuação de agentes convocados para realizar ações antes de responsabilidade do Governo. Ao mesmo tempo, constrói para a instância de recepção a face de interlocutor submisso, para o qual não há alternativa, senão seguir as ordens impostas e, consequentemente, ter seu território invadido.

Com a análise realizada, verifica-se que o interesse deste estudo está em evidenciar que a interação que ocorre na cartilha entre Governo (ANP) e Sociedade (agentes do mercado) não é neutra do ponto de vista das relações de poder. Afinal, a todo o momento a instância de produção faz valer seu status de agência reguladora do Governo (agente controlador, supervisor, normatizador) para levar o outro a aceitar ordens e deveres e acentuar a assimetria dos lugares ocupados. Essa interação entre Governo e um setor da Sociedade revela-se, portanto, bastante agressiva para a face do interlocutor e invasiva de seu território.

Mas vale lembrar que a gestão das faces, territórios e lugares é um processo social e que a face é uma construção (encenação) discursiva e não um traço característico de um indivíduo ou de uma instituição (GOFFMAN, 2009, 2011). Em outros termos, a imagem que uma instância constrói para si na interação não resulta simplesmente de sua vontade de se apresentar de uma ou de outra maneira. Na verdade, a construção da face é um fenômeno bastante complexo, que possui não só uma dimensão microssocial, mas também uma dimensão macrossocial. No nível microssocial, os responsáveis pela elaboração da cartilha, enquanto produtores de um discurso específico, sabem que a ANP precisa se apresentar às organizações privadas como entidade que regula e prescreve de modo autoritário ou rigoroso. Já no nível macrossocial, as agências reguladoras de modo geral e não só a ANP precisam se apresentar como instâncias que zelam pelos serviços públicos prestados à sociedade civil por organizações privadas. Afinal, a criação das agências, bem como seu trabalho regulatório e fiscalizador seriam uma contrapartida da venda (privatização) de organizações estatais.

Nesse sentido, a imagem de instância autoritária que emerge na cartilha da ANP pode ser entendida como a resposta de um Governo que busca se desvencilhar da tarefa de assegurar por conta própria serviços voltados ao cidadão, delegando essa tarefa ao mercado. Essa imagem de instituição que "coloca as empresas no seu devido lugar" pode ser entendida, portanto, como uma estratégia do Governo para dizer implicitamente ao cidadão que, embora muitos serviços tenham passado a estar sob a responsabilidade do mercado, o cidadão não se encontra à mercê do mercado. Afinal, o Governo criou agências reguladoras que vão fiscalizar de modo rigoroso a prestação dos serviços. Assim, restrições históricas e políticas de nível macrossocial ajudam a compreender melhor o que leva uma agência como a ANP a construir uma imagem autoritária e normatizadora no diálogo com setores do mercado. 
Como se vê, a complexidade do diálogo entre Governo e Sociedade se deve, em grande medida, ao fato de o fenômeno da gestão das faces, territórios e lugares tocar as dimensões micro e macrossocial, dimensões que nem sempre são articuladas nos estudos da linguagem.

\section{Considerações finais}

Neste trabalho, propomos aproximar a Análise do Discurso e os Estudos Organizacionais, porque consideramos possível e necessário compreender as organizações de uma perspectiva do discurso. Assim, o diálogo entre esses campos distintos de estudos constitui um caminho interessante ao pesquisador que busca obter um conhecimento aprofundado das relações (de poder, faces, territórios, lugares) que se dão tanto no interior de uma organização, quanto entre uma organização e outras organizações ou entre uma organização e a Sociedade. Afinal, essas relações somente se estabelecem, se perpetuam e se tornam evidentes por meio do discurso e têm ligação profunda com a criação, a manutenção e a extinção das organizações públicas ou privadas.

Para evidenciar a pertinência da aproximação da Análise do Discurso e dos Estudos Organizacionais, apresentamos uma análise de uma cartilha em que a ANP dialoga com agentes do mercado. Desenvolvido à luz do Modelo de Análise Modular do Discurso, o estudo foi capaz de identificar a imagem que a ANP projeta de si ao interagir, por meio da cartilha, com um setor da Sociedade. Com o estudo, obtivemos informações relevantes acerca (i) do contexto de produção e recepção da cartilha, (ii) das imagens recíprocas construídas por meio desse discurso e (iii) de características do processo de negociação entre o Governo (ANP) e a Sociedade (os agentes do mercado) de que a cartilha é o resultado visível ou material. Verificamos, assim, que as estratégias discursivas empregadas na produção da cartilha são reflexos de tensões sociais, históricas, políticas e ideológicas.

CUNHA, Gustavo Ximenes. Analysis of an institutional guideline in a modular approach of discourse complexity. Revista do GEL, v. 13, n. 1, p. 31-55, 2016.

Abstract: This paper articulates Discourse Analysis and Organizational Studies, because it considers necessary to understand organizations (whether public or private) under a discursive perspective. To defend the relevance of this approach, an analysis of a guideline of a Brazilian Government's regulatory agency known as ANP in presented. In the guideline, 
this agency engages with market agents. Developed in the light of the Modular Approach to Discourse Analysis, the study identified the way that ANP looks to itself when it interacts with a sector of society through the guideline. With this study, relevant information about certain issues was obtained. These issues are: (i) the production context and reception of the guideline, (ii) reciprocal images built through this discourse and (iii) characteristics of the negotiation process between the State (ANP) and Society (market agents).

Keywords: Discourse Analysis. Organizational Studies. Modularity.

\section{Referências}

ADAM, J. M. Les textes: types et prototypes. Paris: Nathan, 1997.

AUSTIN, J. L. How to do things with words. Oxford: Clarendon Press, 1962.

BAKHTIN, M.; VOLOCHÍNOV, V. N. Marxismo e filosofia da linguagem. São Paulo: Hucitec, 1986[1929].

BAKHTIN, M. Os gêneros do discurso. In: BAKHTIN, M. Estética da criação verbal. São Paulo: Martins Fontes, 2003. p. 261-306.

BENVENISTE, E. Problemas de linguística geral. São Paulo: Ed. Nacional, Ed. Universidade de São Paulo, 1976. p. 260-276.

BRONCKART, J. P. Atividade de linguagem, textos e discursos: por um interacionismo sócio-discursivo. São Paulo: EDUC, 2007.

BROWN, P.; LEVINSON, S. Politeness: some universals in language use. Cambridge: Cambridge University Press, 1983.

BURGER, M. L'identité négociée: "rapports de place(s)" dans un entretien télédiffusé. Cahiers de linguistique française, n. 17, p. 09-33, 1995.

Positions d'interaction: une approche modulaire. Cahiers de linguistique française, v. 19, p. 11-46, 1997.

CHARAUDEAU, P. Linguagem e discurso: modos de organização. São Paulo: Contexto, 2009.

CHIAPPINI, F. B. Language at work: meeting the challenge of inter-disciplinarity. In: GOUVEIA, C.; SILVESTRE, C.; AZUAGA, L. Discourse, communication and the entreprise: linguistics perspectives. Lisboa: Universidade de Lisboa, 2004. p. 3-16.

CORACINI, M. J. R. F. Um fazer persuasivo: o discurso subjetivo da ciência. Campinas: Pontes, 1991. 
CUNHA, G. X. A construção da narrativa em reportagens. 2013. 601 f. Tese (Doutorado em Linguística) - Faculdade de Letras, Universidade Federal de Minas Gerais, Belo Horizonte, 2013.

Para entender o funcionamento do discurso: uma abordagem modular da complexidade discursiva. Curitiba: Appris, 2014.

DUCROT, O. O dizer e o dito. Campinas: Pontes Editores, 1987.

FILLIETTAZ, L. Actions, activités et discours. 2000. 403 f. Tese (Doutorado em Linguística) - Faculdade de Letras, Universidade de Genebra, Genebra, 2000.

FILLIETTAZ, L.; ROULET, E. The Geneva Model of discourse analysis: an interactionist and modular approach to discourse organization, Discourse Studies, n. 4(3), p. 369-392, 2002.

GOFFMAN, E. La mise en scène de la vie quotidienne: les relations en public. v. 2. Paris: Les éditions de minuit, 1973.

GOFFMAN, E. A representação do eu na vida cotidiana. Petrópolis: Vozes, 2009.

2011.

Ritual de interação: ensaios sobre o comportamento face a face. Petrópolis: Vozes,

GRICE, H. P. Logique et conversation. Communications, v. 30, p. 57-72, 1979.

GRANT, D.; HARDY, C.; OSWICK, C.; PUTNAM, L. Organizational Discourse: exploring the field. In: GRANT, D.; HARDY, C.; OSWICK, C.; PUTNAM, L. (Org.). The Sage Handbook of Organizational Discourse. London: Sage, 2004. p. 1-36.

KERBRAT-ORECCHIONI, C. Análise da conversação: princípios e métodos. São Paulo: Parábola Editorial, 2006.

. Les actes de langage dans le discours: théorie et functionnement. Paris: Armand Colin, 2008.

KOCH, I. G. V. Argumentação e linguagem. São Paulo: Cortez, 2008.

LABOV, W.; FANSHEL, D. Therapeutic discourse. New York: Academic Press, 1977.

LANNA, M. A. L. Ação, experiência e discurso: a gestão da mudança na hipnoterapia. 2005. 350 f. Tese (Doutorado em Linguística) - Faculdade de Letras, Universidade Federal de Minas Gerais, Belo Horizonte, 2005.

MAINGUENEAU, D. Discurso e Análise do Discurso. In: SIGNORINI, I. (Org.).

[Re]discutir texto, gênero e discurso. São Paulo: Parábola Editorial, 2008. p. 135-156.

MARINHO, J. H. C. Uma abordagem modular e interacionista da organização do discurso. Revista da Anpoll, n. 16, p. 75-100, 2004. 
MOZDZENSKI, L. P. A cartilha jurídica: aspectos sócio-históricos, discursivos e multimodais. 2006. 195 f. Dissertação (Mestrado em Linguística) - Faculdade de Letras, Universidade Federal de Pernambuco, Recife, 2006.

MUMBY, D. K.; CLAIR, R. P. Organizational Discourse. In: VAN DIJK, T. A. (Org.). Discourse as social interaction. London: Sage, 1997. p. 181-205.

PACHECO, R. S. Regulação no Brasil: desenho das agências e formas de controle. Revista de Administração Pública, Rio de Janeiro, v. 40, n. 4, p. 523-543, 2006.

ROULET, E. Étude des plans d'organisation syntaxique, hiérarchique et référentiel du dialogue: autonomie et interrelations modulaires. Cahiers de linguistique française, v. 17, p. 123- 140, 1995.

ROULET, E. Um modelo e um instrumento de análise sobre a organização do discurso. In: MARI, H. et al. (Org.). Fundamentos e Dimensões da Análise do Discurso. Belo Horizonte: Núcleo de Análise do Discurso - FALE/UFMG, 1999. p. 139-171.

ROULET, E.; FILLIETTAZ, L.; GROBET, A. Un modèle et un instrument d'analyse de l'organisation du discours. Berne: Lang, 2001.

SACKS, H.; SCHEGLOFF, E.; JEFFERSON, G. Sistemática elementar para a organização da tomada de turnos para a conversa. Veredas, Juiz de Fora, v. 7 (1), p. 09-73, 2003[1974].

VALÉRIO, K. M. Dinâmicas interativas no discurso da mulher: o papel da inserção social. Belo Horizonte: Faculdade de Letras/UFMG, 2003.

VION, R. La communication verbale: analyse des interactions. Paris: Hachette, 1992.

Submetido em 28/03/2015

Aceito em 18/11/2015 